\title{
Risk Factors Association with Severity of White Matter Lesions on Magnetic Resonance Imaging
}

Masaaki Nemoto, Hiroyuki Masuda, Nauyuki Harada, Nobuo Sugo*, Sayaka Terazono, Yasuhiro Node, Kei Uchino, Shinichi Okonogi, Yutaka Fuchinoue, Yuki Sakaeyama and Kosuke Kondo

Department of Neurosurgery (Omori), School of Medicine, Faculty of Medicine, Toho University, Ota-ku, Tokyo, Japan

"Corresponding author: Nobuo Sugo, MD, PhD, Department of Neurosurgery (Omori), School of Medicine, Faculty of Medicine, Toho University, 6-11-1, Omori-nishi, Ota-ku, Tokyo, 143-8541, Japan ,Tel: +81-3-3762-4151; Fax: +81-3-3298-4847; E-mail: nsugo@med.toho-u.ac.jp

Received date: May 11, 2017; Accepted date: May 24, 2017; Published date: May 30, 2017

Copyright: @ 2017 Nemoto M. This is an open-access article distributed under the terms of the Creative Commons Attribution License, which permits unrestricted use, distribution, and reproduction in any medium, provided the original author and source are credited.

\section{Abstract}

Background: The objective of this study was to identify risk factors involved in the severity of deep subcortical white matter (DSWMH) and periventricular (PVH) hyper-intensities on MRI, which are white matter lesions.

Methods: The subjects were 506 consecutive asymptomatic patients examined in a brain dry-dock. The severities of DSWMH and PVH were classified using the Fazekas scale. Regarding risk factors, in addition to sex, age, cigarette smoking, alcohol drinking, and renal function, hypertension, diabetes, dyslipidemia, and gout were divided into 3 grades: without the disease, being treated, or untreated, and evaluated.

Results: Regarding the normal group as grade 0 on the Fazekas scale, the relationship between the DSWMH severity and each risk factor was investigated. In addition to an increase with aging $(p<0.001)$, the DSWMH severity increased in the order of the state of hypertension from without the disease, being treated, or untreated $(p<0.01)$. The PVH severity increased with aging $(p<0.001)$ and in the order of the state of diabetes mellitus from without the disease, being treated, or untreated $(p<0.001)$.

Conclusion: Strict treatment of each disease may prevent aggravation of DSWMH and PVH, respectively, reducing incidences of stroke and dementia in the future.

Keywords: White matter lesions; Deep subcortical white mater hyper-intensity; Periventricular hyper-intensity; Age; Hypertension; Diabetes mellitus

\section{Introduction}

White matter lesions (WMLs) are typical asymptomatic lesions observed on T2-weighted magnetic resonance imaging (MRI) and fluid-attenuated inversion recovery imaging (FLAIR) of the head $[1,2]$. WMLs are classified into deep subcortical white matter (DSWMH) and periventricular $(\mathrm{PVH})$ hyper-intensities, and the severity of each type is evaluated based on expansion of lesions on imaging. It has been reported that clinically, WMLs increase the risk of ischemic stroke, dementia, and death [2-4]. WMLs were also reported to be involved in age and cerebrovascular disorder-associated depressive symptoms, reduction of the motor function, and urinary incontinence $[2,5]$. Therefore, inhibition of development and aggravation of WMLs is important for prevention of brain diseases in the aging society. Many studies on risk factors involved in formation of WMLs have been performed, and age [6,7], hypertension [6,8], diabetes [9], chronic kidney disease (CKD) [7], carotid stenosis [10], and non-valvular atrial fibrillation [11] have been reported. On the other hand, risk factors influencing the severity of WMLs are still controversial $[3,4,6,8,9,12,13]$.

The objective of this study was to identify risk factors involved in the severity of DSWMH and PVH on MRI, which are WMLs, in asymptomatic patients.

\section{Materials and Methods}

In Japan, there is a health diagnosis system called a brain dry-dock in which asymptomatic healthy subjects check their brains by their own expense. At the same time, it also conducts interview, medical examination, electrocardiogram and blood test etc. The subjects were 506 consecutive asymptomatic patients examined in a brain dry-dock at Toho University Omori Medical Center between April 2007 and March 2015. They were retrospectively investigated. All patients underwent brain MRI on a $1.5 \mathrm{~T}$ MRI (Excelart Vantage MRT-2003/P3; Toshiba, Tokyo, Japan), including axial T2- weighted, T1-weighted imaging, FLAIR, diffusion-weighted imaging (DWI) performed with 5-mm slice thickness, and three dimensional time of flight MR angiography. WMLs were defined as hyper-intense lesions on FLAIR and T2 images, which are usually not seen on T1-weighted images, or faint hypo-intensity. MR images were read by 2 board certified members of the Japan Neurosurgical Society. Patients with ischemic stroke, such as lacunar infarction or cardiogenic cerebral embolism, were excluded.

\section{Fazekas scale}

WMLs were classified into DSWMH and PVH according to the Fazekas scale [1]. DSWMH was categorized as: grade 0, absent; grade 1 , punctuate foci; grade 2, beginning confluence of foci; or grade 3 , large confluent areas. PVH was categorized as: grade 0 , absent; grade 1 , caps or pencil-thin lining; grade 2, smooth halo; or grade 3, irregular $\mathrm{PVH}$ extending into the deep white matter. Accordingly, normal 
Citation: $\quad$ Nemoto M, Masuda H, Harada H, Sugo N, Terazono S, et al. (2017) Risk Factors Association with Severity of White Matter Lesions on Magnetic Resonance Imaging. Gen Med (Los Angeles) 5: 290. doi:10.4172/2327-5146.1000290

Page 2 of 7

subjects were classified with grade-0 DSWMH and PVH. When both DSWMH and PVH were present, the patient was included in the Fazekas scale-based severe group.

\section{Risk factors}

Sex, age, hypertension, diabetes, dyslipidemia, gout, cigarette smoking, alcohol drinking, and renal function were investigated based on interviews from all patients. Regarding hypertension, diabetes, dyslipidemia, and gout, the patients were divided into 3 grades: (a) without the disease, (b) being treated, or (c) untreated. Untreated hypertension was defined as systolic blood pressure $\geq 140 \mathrm{mmHg}$ at the time of the first examination. Untreated diabetes was defined as HbAlc (NGSP) $\geq 6.3 \%$ on blood testing, dyslipidemia was defined as LDL-cholesterol $\geq 140 \mathrm{mg} / \mathrm{dl}$ or total cholesterol $\geq 220 \mathrm{mg} / \mathrm{dl}$, and gout was defined as uric acid $\geq 7.1 \mathrm{mg} / \mathrm{dl}$. The renal function was evaluated based on the estimated glomerular filtration rate (eGFR).

\section{Statistical analysis}

Numerical variables were analyzed using the t-test (IBM SPSS Statistics, ver.19, IBM Co., New York, USA). For binary and ternary data, the chi-square test was used. Regarding the correlation between the severity of WMLs on MRI and each variable, multiple regression analysis was performed regarding the Fazekas scale grades "0"- "III" as values. $\mathrm{P}<0.05$ was regarded as significant. This study was approved by the Ethics Committee of Toho University Omori medical center (approved number: M16112)

\section{Results}

Excluding 13 patients with ischemic stroke on MRI, such as lacunar infarction or cardiogenic cerebral embolism, from the 506 patients, 281 normal subjects, 162 patients with DSWMH (Fazekas scale grade I-III), and 50 patients with PVH (grade I-III), 493 subjects in total, were investigated.

\begin{tabular}{|c|c|c|c|c|c|}
\hline \multirow[t]{2}{*}{ Variables } & \multicolumn{5}{|c|}{ Fazekas grade (DSWMH) } \\
\hline & 0 [Normal] & 1 & II & III & $|+| I+I I I$ \\
\hline Number & 281 & 95 & 60 & 7 & 162 \\
\hline Male & $155(55.2)$ & 55 & 25 & 4 & $84(51.9)$ \\
\hline Age & $52.8 \pm 13.6$ & $62.5 \pm 11.1$ & $68.7 \pm 9.3$ & $69.0 \pm 7.1$ & $65.1 \pm 10.9$ \\
\hline $\mathrm{HT}(\mathrm{a} / \mathrm{b} / \mathrm{c})$ & $226 / 18 / 37$ & $65 / 20 / 10$ & $32 / 10 / 18$ & $1 / 2 / 4$ & $98 / 3232$ \\
\hline SBP & $122.6 \pm 17.0$ & $128.9 \pm 16.0$ & $133.4 \pm 15.2$ & $148.9 \pm 14.0$ & $131.5 \pm 16.1$ \\
\hline DBP & $73.1 \pm 12.5$ & $75.3 \pm 11.9$ & $74.1 \pm 12.2$ & $82.9 \pm 10.9$ & $75.2 \pm 12.0$ \\
\hline $\mathrm{DM}(\mathrm{a} / \mathrm{b} / \mathrm{c})$ & 259/10/12 & $88 / 2 / 5$ & $51 / 1 / 8$ & $6 / 0 / 1$ & $145 / 3 / 14$ \\
\hline $\mathrm{HbA} 1 \mathrm{c}$ & $5.5 \pm 0.6$ & $5.7 \pm 0.6$ & $5.8 \pm 0.6$ & $5.4 \pm 0.1$ & $5.7 \pm 0.6$ \\
\hline Blood sugar & $102.3 \pm 18.8$ & $106.3 \pm 23.4$ & $106.0 \pm 22.8$ & $102.1 \pm 10.5$ & $106.0 \pm 22.7$ \\
\hline Dyslipidemia (a/b/c) & $173 / 14 / 94$ & $50 / 14 / 31$ & $36 / 9 / 15$ & $4 / 1 / 2$ & $90 / 2448$ \\
\hline T-cho & $202.5 \pm 34.5$ & $212.3 \pm 34.0$ & $205.6 \pm 34.4$ & $199.9 \pm 46.4$ & $209.3 \pm 34.7$ \\
\hline LDL & $122.6 \pm 29.5$ & $132.7 \pm 29.8$ & $122.9 \pm 31.4$ & $122.4 \pm 48.1$ & $128.6 \pm 31.5$ \\
\hline HDL & $64.5 \pm 18.0$ & $65.1 \pm 16.3$ & $69.6 \pm 16.4$ & $63.1 \pm 13.2$ & $66.7 \pm 16.3$ \\
\hline TG & $110.3 \pm 95.4$ & $114.2 \pm 68.3$ & $93.5 \pm 46.6$ & $92.6 \pm 35.9$ & $105.5 \pm 60.5$ \\
\hline Gout $(a / b / c)$ & $273 / 6 / 2$ & $90 / 4 / 1$ & $56 / 4 / 0$ & $7 / 0 / 0$ & $153 / 8 / 1$ \\
\hline Uric acid & $5.5 \pm 1.3$ & $6.4 \pm 7.1$ & $5.3 \pm 1.3$ & $5.6 \pm 0.3$ & $6.0 \pm 5.8$ \\
\hline Smoking & $98(53.6)$ & 27 & 14 & 0 & $41(25.3)$ \\
\hline Alcohol & $122(76.7)$ & 43 & 27 & 2 & $72(44.4)$ \\
\hline eGFR & $79.9 \pm 19.0$ & $71.3 \pm 12.4$ & $71.9 \pm 20.2$ & $73.9 \pm 8.0$ & $71.7 \pm 15.6$ \\
\hline
\end{tabular}

(a) without the disease; (b) being treated; (c) untreated; Values are expressed as $\mathrm{n}$ (\%). HT: Hypertension; SBP: Systolic Blood Pressure; DBP: Diastolic Blood Pressure; DM: Diabetes Mellitus; LDL: LDL-Cholesterol; HDL: HDL-Cholesterol; TG: Triglyceride; eGFR: Estimate Glomerular Filtration Rate

Table 1: Clinical and demographic characteristics of DSWMH.

\section{Risk factors involved in the presence or absence of WMLs}

The clinical and demographic characteristics of DSWMH are shown in Table 1. On comparison between the normal group and the group combining Fazekas scale grade I-III cases of DSWMH, significant differences were noted in the age, hypertension, systolic blood pressure, HbAlc, LDL-cholesterol, cigarette smoking, and eGFR on 
Citation: $\quad$ Nemoto M, Masuda H, Harada H, Sugo N, Terazono S, et al. (2017) Risk Factors Association with Severity of White Matter Lesions on Magnetic Resonance Imaging. Gen Med (Los Angeles) 5: 290. doi:10.4172/2327-5146.1000290

Page 3 of 7

univariate analysis (Table 2). On multivariate analysis, age was an independent risk factor of DSWMH formation. On comparison between the group combining Fazekas scale grade I-III cases of PVH (Table 3) and the normal group (Table 1), significant differences were noted in age, hypertension, systolic blood pressure, diabetes, HbAlc, blood sugar, gout, and eGFR on univariate analysis (Table 4). On multivariate analysis, age was an independent risk factor of $\mathrm{PVH}$ formation similarly to that for DSWMH formation.

\begin{tabular}{|c|c|c|c|c|c|c|}
\hline \multirow[t]{2}{*}{ Variables } & \multicolumn{3}{|c|}{ Univariate } & \multicolumn{3}{|c|}{ Multivariable } \\
\hline & OR & $95 \% \mathrm{Cl}$ & $p$ value & OR & $95 \% \mathrm{Cl}$ & $p$ value \\
\hline Male & 1.14 & $0.78-1.68$ & 0.5 & 0.96 & $0.42-2.18$ & 0.92 \\
\hline Age & 1.08 & $1.06-1.10$ & $<0.001^{\star \star}$ & 1.08 & $1.04-1.11$ & $<0.001^{* *}$ \\
\hline HT & 1.59 & $1.23-2.05$ & $<0.001^{\star \star}$ & 0.95 & $0.53-1.70$ & 0.87 \\
\hline SBP & 1.03 & $1.02-1.04$ & $<0.001^{\star \star}$ & 1.01 & $0.98-1.05$ & 0.4 \\
\hline DBP & 1.01 & $1.00-1.03$ & 0.08 & 1.01 & $0.97-1.05$ & 0.53 \\
\hline DM & 1.32 & $0.90-1.93$ & 0.15 & 0.79 & $0.31-2.02$ & 0.63 \\
\hline HbA1c & 1.92 & $1.19-3.09$ & $0.01^{\star \star}$ & 1.42 & $0.64-3.16$ & 0.39 \\
\hline Blood sugar & 1.01 & $1.00-1.02$ & 0.07 & 1 & $0.98-1.03$ & 0.87 \\
\hline Dyslipidemia & 1.03 & $0.83-1.27$ & 0.81 & 0.78 & $0.53-1.14$ & 0.21 \\
\hline T-cho & 1.01 & $1.00-1.01$ & 0.05 & 0.99 & $0.95-1.02$ & 0.47 \\
\hline LDL & 1.01 & $1.00-1.01$ & $0.05^{*}$ & 1.01 & $0.98-1.05$ & 0.44 \\
\hline HDL & 1.01 & $1.00-1.02$ & 0.21 & 1.01 & $0.97-1.04$ & 0.73 \\
\hline TG & 1 & $1.00-1.00$ & 0.57 & 1 & $0.99-1.00$ & 0.83 \\
\hline Gout & 1.55 & $0.71-3.42$ & 0.27 & 1.27 & $0.44-3.65$ & 0.66 \\
\hline Uric acid & 1.04 & $0.95-1.14$ & 0.4 & 1.03 & $0.93-1.14$ & 0.56 \\
\hline Smoking & 0.63 & $0.41-0.97$ & $0.04^{*}$ & 1.27 & $0.57-2.85$ & 0.56 \\
\hline Alcohol & 1.04 & $0.71-1.54$ & 0.83 & 1.21 & $0.58-2.52$ & 0.62 \\
\hline eGFR & 0.97 & $0.96-0.98$ & $<0.001^{* *}$ & 1 & $0.97-1.02$ & 0.87 \\
\hline
\end{tabular}

Table 2: A comparison between normal group and DSWMH group (grade I III).

\begin{tabular}{|c|c|c|c|c|}
\hline \multirow[t]{2}{*}{ Variables } & \multicolumn{4}{|c|}{ Fazekas grade (PVH) } \\
\hline & I & II & III & $|+||+| I \mid$ \\
\hline Number & 28 & 13 & 9 & 50 \\
\hline Male & $17(60.7)$ & $7(53.8)$ & $5(55.6)$ & $29(58.0)$ \\
\hline Age & $69.1 \pm 9.5$ & $72.3 \pm 7.4$ & $75.4 \pm 5.8$ & $71.1 \pm 8.7$ \\
\hline HT $(a / b / c)$ & $17 / 6 / 5$ & $7 / 3 / 3$ & $2 / 3 / 4$ & $26 / 12 / 12$ \\
\hline SBP & $132.8 \pm 24.5$ & $136.0 \pm 16.6$ & $139.6 \pm 6.0$ & $134.8 \pm 20.3$ \\
\hline DBP & $76.1 \pm 24.8$ & $73.7 \pm 14.4$ & $72.9 \pm 9.2$ & $74.9 \pm 20.1$ \\
\hline$D M(a / b / c)$ & $26 / 1 / 1$ & $10 / 1 / 2$ & $2 / 2 / 5$ & $38 / 4 / 8$ \\
\hline HbA1c & $5.8 \pm 0.7$ & $5.9 \pm 0.7$ & $6.6 \pm 0.8$ & $6.0 \pm 0.8$ \\
\hline
\end{tabular}


Citation: $\quad$ Nemoto M, Masuda H, Harada H, Sugo N, Terazono S, et al. (2017) Risk Factors Association with Severity of White Matter Lesions on Magnetic Resonance Imaging. Gen Med (Los Angeles) 5: 290. doi:10.4172/2327-5146.1000290

Page 4 of 7

\begin{tabular}{|l|l|l|l|l|}
\hline Blood sugar & $102.5 \pm 17.4$ & $110.5 \pm 18.3$ & $135.4 \pm 45.2$ & $110.5 \pm 27.1$ \\
\hline Dyslipidemia (a/b/c) & $21 / 5 / 2$ & $10 / 2 / 1$ & $1 / 3 / 5$ & $32 / 10 / 8$ \\
\hline T-cho & $206.4 \pm 20.5$ & $194.8 \pm 35.5$ & $199.0 \pm 28.5$ & $202.1 \pm 26.5$ \\
\hline LDL & $126.3 \pm 19.4$ & $116.3 \pm 27.0$ & $121.1 \pm 30.7$ & $122.8 \pm 23.6$ \\
\hline HDL & $67.6 \pm 17.0$ & $67.1 \pm 12.1$ & $64.6 \pm 9.0$ & $66.9 \pm 14.5$ \\
\hline TG & $94.9 \pm 55.6$ & $94.8 \pm 50.0$ & $112.7 \pm 28.1$ & $98.0 \pm 49.9$ \\
\hline Gout (a/b/c) & $24 / 2 / 2$ & $12 / 1 / 0$ & $7 / 1 / 1$ & $43 / 4 / 3$ \\
\hline Uric acid & $5.7 \pm 1.2$ & $5.6 \pm 1.1$ & $5.6 \pm 0.8$ & $5.6 \pm 1.0$ \\
\hline Smoking & $9(47.4)$ & $2(18.2)$ & $2(28.6)$ & 13 (36.0) \\
\hline Alcohol & 11 (64.7) & $6(85.7)$ & $1(12.5)$ & 18 (36.0) \\
\hline eGFR & $67.7 \pm 17.2$ & $68.7 \pm 13.5$ & $62.7 \pm 12.4$ & $67.1 \pm 15.4$ \\
\hline $\begin{array}{l}\text { (a): without the disease; (b) being treated; (c) untreated; Values are expressed as } \mathrm{n} \text { (\%). HT: Hypertension; SBP: Systolic Blood Pressure; DBP: Diastolic Blood } \\
\text { Pressure; DM: Diabetes Mellitus; LDL: LDL-Cholesterol; HDL: HDL-Cholesterol; TG: Triglyceride; eGFR: Estimate Glomerular Filtration Rate }\end{array}$ & & \\
\hline
\end{tabular}

Table 3: Clinical and demographic characteristics of PVH.

\begin{tabular}{|c|c|c|c|c|c|c|}
\hline \multirow[t]{2}{*}{ Variables } & \multicolumn{3}{|c|}{ Univariate } & \multicolumn{3}{|c|}{ Multivariable } \\
\hline & OR & $95 \% \mathrm{Cl}$ & $p$ value & OR & $95 \% \mathrm{Cl}$ & $p$ value \\
\hline Male & 0.89 & $0.48-1.64$ & 0.71 & 0.2 & $0.04-1.12$ & 0.07 \\
\hline Age & 1.14 & $1.10-1.18$ & $<0.001^{* *}$ & 1.3 & $1.14-1.47$ & $<0.001^{* *}$ \\
\hline HT & 1.85 & $1.29-2.63$ & $<0.001^{* *}$ & 1.47 & $0.37-5.79$ & 0.58 \\
\hline SBP & 1.04 & $1.02-1.06$ & $<0.001^{* *}$ & 0.99 & $0.93-1.05$ & 0.71 \\
\hline DBP & 1.01 & $0.99-1.03$ & 0.39 & 1.04 & $0.99-1.10$ & 0.14 \\
\hline DM & 2.19 & $1.38-3.46$ & $<0.001^{* *}$ & 1.84 & $0.46-7.34$ & 0.39 \\
\hline HbA1c & 2.53 & $1.45-4.39$ & $0.001^{* *}$ & 0.73 & $0.16-3.30$ & 0.69 \\
\hline Blood sugar & 1.01 & $1.00-1.03$ & $0.02^{*}$ & 1.04 & $0.99-1.10$ & 0.11 \\
\hline Dyslipidemia (a/b/c) & 0.77 & $0.54-1.10$ & 0.16 & 0.47 & $0.20-1.09$ & 0.08 \\
\hline T-cho & 1 & $0.99-1.01$ & 0.93 & 0.96 & $0.90-1.03$ & 0.25 \\
\hline LDL & 1 & $0.99-1.01$ & 0.97 & 1.03 & $0.97-1.10$ & 0.38 \\
\hline HDL & 1.01 & $0.99-1.02$ & 0.38 & 1.02 & $0.96-1.08$ & 0.51 \\
\hline TG & 1 & $0.99-1.00$ & 0.38 & 1 & $0.99-1.01$ & 0.59 \\
\hline Gout & 3.41 & $1.57-7.44$ & $0.002^{* *}$ & 0.61 & $0.14-2.73$ & 0.52 \\
\hline Uric acid & 1.09 & $0.81-1.46$ & 0.59 & 0.7 & $0.34-1.43$ & 0.32 \\
\hline Smoking & 0.66 & $0.33-1.29$ & 0.22 & 2.25 & $0.40-12.65$ & 0.36 \\
\hline Alcohol & 0.73 & $0.39-1.37$ & 0.33 & 3.96 & $0.73-21.44$ & 0.11 \\
\hline eGFR & 0.95 & $0.93-0.97$ & $<0.001^{* *}$ & 0.99 & $0.93-1.05$ & 0.73 \\
\hline
\end{tabular}

Table 4: A comparison between normal group and PVH group (grade I III). 
Citation: $\quad$ Nemoto M, Masuda H, Harada H, Sugo N, Terazono S, et al. (2017) Risk Factors Association with Severity of White Matter Lesions on Magnetic Resonance Imaging. Gen Med (Los Angeles) 5: 290. doi:10.4172/2327-5146.1000290

Page 5 of 7

\section{Risk factors involved in the severity of WMLs on MRI}

When the relationship between the DSWMH severity and each risk factor, regarding the normal group as grade 0 on the Fazekas scale, the grade aggravated as age advanced $(\mathrm{p}<0.001)$ and systolic blood pressure rose $(\mathrm{p}<0.05)$ (Table 5$)$. When analysis was repeated collectively regarding hypertension, diabetes, hyperlipidemia, and gout as representative variables, in addition to an increase with aging $(p<0.001)$, the severity on the Fazekas scale increased in the order of the state of hypertension from without the disease, being treated, and untreated $(\mathrm{p}<0.01)($ Table 5).

Regarding PVH, aging $(\mathrm{p}<0.001)$, diabetes mellitus $(\mathrm{p}<0.01)$, and a high blood sugar level $(\mathrm{p}<0.05)$ were associated with the severity on the Fazekas scale (Table 6). On analysis with representative variables, the PVH severity increased with aging $(\mathrm{p}<0.001)$ and in the order of the state of diabetes mellitus from without the disease, being treated, and untreated $(\mathrm{p}<0.001)$ (Table 6).

\begin{tabular}{|c|c|c|c|c|c|}
\hline Variables & Partial regression coefficient & $\mathrm{p}$ value & Representative variables & Partial regression coefficient & $p$ value \\
\hline Male & 0.022 & 0.86 & Male & -0.04 & 0.57 \\
\hline Age & 0.021 & $<0.001^{* \star *}$ & Age & 0.02 & $<0.001^{* * *}$ \\
\hline$H T(a / b / c)$ & 0.012 & 0.89 & \multirow{3}{*}{$\mathrm{HT}(\mathrm{a} / \mathrm{b} / \mathrm{c})$} & \multirow{3}{*}{0.16} & \multirow{3}{*}{$<0.01^{* *}$} \\
\hline SBP & 0.007 & $<0.05^{*}$ & & & \\
\hline DBP & -0.001 & 0.92 & & & \\
\hline$D M(a / b / c)$ & 0.15 & 0.31 & \multirow{3}{*}{$\mathrm{DM}(\mathrm{a} / \mathrm{b} / \mathrm{c})$} & \multirow{3}{*}{0.07} & \multirow{3}{*}{0.34} \\
\hline HbA1c & 0.068 & 0.58 & & & \\
\hline Blood sugar & -0.003 & 0.48 & & & \\
\hline Dyslipidemia (a/b/c) & -0.047 & 0.41 & \multirow{5}{*}{$\mathrm{HL}(\mathrm{a} / \mathrm{b} / \mathrm{c})$} & \multirow{5}{*}{-0.03} & \multirow{5}{*}{0.44} \\
\hline T-cho & 0 & 0.42 & & & \\
\hline LDL & 0 & 0.52 & & & \\
\hline HDL & 0.004 & 0.44 & & & \\
\hline TG & 0 & 0.98 & & & \\
\hline Gout (a/b/c) & 0.101 & 0.49 & \multirow{2}{*}{ Gout $(a / b / c)$} & \multirow{2}{*}{0.02} & \multirow{2}{*}{0.88} \\
\hline Uric acid & 0 & 0.99 & & & \\
\hline Smoking & 0.064 & 0.6 & Smoking & -0.12 & 0.14 \\
\hline Alcohol & 0.03 & 0.79 & Alcohol & 0.02 & 0.82 \\
\hline eGFR & -0.002 & 0.6 & eGFR & 0 & 0.77 \\
\hline
\end{tabular}

Table 5: A correlation with severity in DSWMH and risk factors.

\begin{tabular}{|c|c|c|c|c|c|}
\hline Variables & Partial regression coefficient & $p$ value & Representative variables & Partial regression coefficient & $p$ value \\
\hline Male & -0.133 & 0.36 & Male & -0.09 & 0.2 \\
\hline Age & 0.02 & $<0.001^{* * *}$ & Age & 0.02 & $<0.001^{* * *}$ \\
\hline $\mathrm{HT}(\mathrm{a} / \mathrm{b} / \mathrm{c})$ & 0.037 & 0.74 & \multirow[t]{3}{*}{$H T(a / b / c)$} & \multirow[t]{3}{*}{0.06} & \multirow[t]{3}{*}{0.2} \\
\hline SBP & 0.007 & 0.22 & & & \\
\hline DBP & -0.009 & 0.09 & & & \\
\hline
\end{tabular}


Page 6 of 7

\begin{tabular}{|c|c|c|c|c|c|}
\hline $\mathrm{DM}(\mathrm{a} / \mathrm{b} / \mathrm{c})$ & 0.377 & $<0.01^{* *}$ & \multirow[t]{3}{*}{$\mathrm{DM}(\mathrm{a} / \mathrm{b} / \mathrm{c})$} & \multirow[t]{3}{*}{0.34} & \multirow[t]{3}{*}{$<0.001^{* * *}$} \\
\hline HbA1c & -0.117 & 0.4 & & & \\
\hline Blood sugar & 0.011 & $<0.05^{*}$ & & & \\
\hline Dyslipidemia (a/b/c) & 0.01 & 0.89 & \multirow[t]{5}{*}{$\mathrm{HL}(\mathrm{a} / \mathrm{b} / \mathrm{c})$} & \multirow[t]{5}{*}{-0.05} & \multirow[t]{5}{*}{0.15} \\
\hline T-cho & -0.01 & 0.32 & & & \\
\hline LDL & 0.003 & 0.66 & & & \\
\hline HDL & 0 & 0.44 & & & \\
\hline TG & 0 & 0.88 & & & \\
\hline Gout (a/b/c) & 0.046 & 0.75 & \multirow[t]{2}{*}{ Gout $(a / b / c)$} & \multirow[t]{2}{*}{0.04} & \multirow[t]{2}{*}{0.77} \\
\hline Uric acid & -0.054 & 0.34 & & & \\
\hline Smoking & 0.029 & 0.84 & Smoking & -0.05 & 0.52 \\
\hline Alcohol & 0.014 & 0.92 & Alcohol & -0.05 & 0.46 \\
\hline eGFR & -0.004 & 0.3 & eGFR & -0.003 & 0.17 \\
\hline
\end{tabular}

Table 6: A correlation with severity in PVH and risk factors.

\section{Discussion}

Many studies demonstrated a strong influence of age out of several risk factors involved in development of WMLs [6-9,14,15]. Age was also an independent risk factor for the presence or absence of DSWMH and PVH, which are WMLs, in our study.

Not only the presence but also severity of WMLs on MRI are regarded as important findings to predict symptoms in the future $[3,4]$. It has been reported that the incidence of stroke was 3-times or higher in the group with severe WMLs than with mild WMLs [4]. Risk factors involved in the severities of DSWMH and PVH, which are WMLs, include aging, hypertension, diabetes, and CKD $[6,9,12,13]$. Chou et al. reported that the severities of DSWMH and PVH on the Fazekas scale were correlated with aging in patients who developed ischemic stroke [12]. Kuriyama et al. compared asymptomatic patients with DSWMH on MRI between those without changes on MRI and with aggravation of imaging findings after 5 years. The incidences of hypertension and CKD were higher in the group with aggravation of imaging findings. They stated that these were factors aggravating DSWMH [9] and many patients were diabetic in this group compared with the normal group [9]. Shrestha et al. reported that blood pressure was correlated with the severities of DSWMH and PVH on the Fazekas scale in asymptomatic patients [13]. Han et al. observed that plasma intercellular adhesion molecule-1 (ICAM-1) increased as an independent risk factor associated with the severity of WMLs, in addition to aging and hypertension [6]. In our study, aging was closely correlated with the severities of both DSWMH and PVH on imaging. On the other hand, control of hypertension was associated with the severity of DSWMH, whereas diabetes was involved with $\mathrm{PVH}$, showing that although DSWMH and PVH are generally included in the same category as WMLs, the risk factor involved in aggravation was different between DSWMH and PVH. Pathological findings are also different between DSWMH and PVH. Dilated perivascular space, demyelination, arteriosclerosis, and chronic ischemic damage are considered to be the essence of the pathology of DSWMH [16-18]. Fazekas et al. compared DSWMH on MRI before death with the pathological findings in 6 autopsied patients. They observed reduction of the myelin sheath accompanied by neuropil atrophy around fibrohyalinotic arteries, such that they regarded DSWMH as minor perivascular damage rather than cerebral infarction [1]. They also pointed out that it was extensive ischemic damage accompanied by advanced microangiopathy $[19,20]$. In contrast, the pathological findings of PVH have been reported to be disruption of the ependymal lining due to subependymal widening of the extracellular space [21]. Regarding the developmental mechanism of $\mathrm{PVH}$, it is hypothesized as an increase in interstitial fluid or impairment of transport of interstitial fluid to the ventricle $[18,19]$. While development and aggravation are basically due to ischemic vascular damage and arteriosclerosis in both DSWMH and PVH [16-20], it is possible that mechanisms associated with different risk factors are added to each type, resulting in the differences in pathological and imaging findings.

The severity of DSWMH on the Fazekas scale increased in the order of the state of hypertension from without the disease, being treated, and untreated, suggesting that treatment of hypertension is useful for preventing progression of DSWMH. van Dijk et al. also stated that systolic blood pressure elevation was associated with severe WMLs; many WMLs were more severe in patients with insufficient control of hypertension than in patients with well controlled hypertension, and treatment of hypertension reduced aggravation of WMLs [22]. For $\mathrm{PVH}$, active treatment of diabetes may be important for inhibiting aggravation.

\section{Conclusion}

The severities of DSWMH and PVH on imaging were associated with hypertension and diabetes, respectively. It is expected that strict treatment of the diseases may prevent aggravation of DSWMH and $\mathrm{PVH}$, respectively, decreasing incidences of stroke and dementia in the future. 
Citation: $\quad$ Nemoto M, Masuda H, Harada H, Sugo N, Terazono S, et al. (2017) Risk Factors Association with Severity of White Matter Lesions on Magnetic Resonance Imaging. Gen Med (Los Angeles) 5: 290. doi:10.4172/2327-5146.1000290

Page 7 of 7

\section{Competing Interests}

The authors declare that there is no conflict of interests regarding the publication of this paper.

\section{Acknowledgement}

We thank Chiaki Nishimura, PhD, Professor Emeritus of Toho University, for helping us with the statistical processing.

\section{References}

1. Fazekas F, Kleinert R, Offenbacher H, Payer F, Schmidt R, et al. (1991) The morphologic correlate of incidental punctate white matter hyperintensities on MR images. AJNR Am J Neuroradiol 5: 915-921.

2. Debette S, Markus HS (2010) The clinical importance of white matter hyperintensities on brain magnetic resonance imaging: Systematic review and meta-analysis. BMJ 341: c3666.

3. Zhang C, Wang Y, Zhao X, Wang C, Liu L, et al. (2014) Factors associated with severity of leukoaraiosis in first-ever lacunar stroke and atherosclerotic ischemic stroke patients. J Stroke Cerebrovasc Dis 23: 2862-2868.

4. Vermeer SE, Hollander M, van Dijk EJ, Hofman A, Koudstaal PJ, et al. (2003) Silent brain infarcts and white matter lesions increase stroke risk in the general population: The Rotterdam Scan Study. Stroke 34:1126-1129

5. Poggesi A, Pantoni L, Inzitari D, Fazekas F, Ferro J, et al. (2011) A decade of the LADIS (Leukoaraiosis And DISability) Study: What have we learned about white matter changes and small-vessel disease? Cerebrovasc Dis 32: 577-588.

6. Han JH, Wong KS, Wang YY, Fu JH, Ding D, et al. (2009) Plasma level of sICAM-1 is associated with the extent of white matter lesion among asymptomatic elderly subjects. Clin Neurol Neurosurg 11: 847-851.

7. Toyoda G, Bokura H, Mitaki S, Onoda K, Oguro H, et al. (2015) Association of mild kidney dysfunction with silent brain lesions in neurologically normal subjects. Cerebrovasc Dis Extra 5: 22-27.

8. de Leeuw FE, de Groot JC, Oudkerk M, Witteman JC, Hofman A, et al. (2002) Hypertension and cerebral white matter lesions in a prospective cohort study. Brain 125: 765-772.

9. Kuriyama N, Mizuno T, Ohshima Y, Yamada K, Ozaki E, et al. (2013) Intracranial deep white matter lesions (DWLs) are associated with chronic kidney disease (CKD) and cognitive impairment: A 5-year follow-up magnetic resonance imaging (MRI) study. Arch Gerontol Geriatr 56: 55-60.
10. Kandiah N, Goh O, Mak E, Marmin M, Ng A (2012) Carotid stenosis: A risk factor for cerebral white-matter disease. J Stroke Cerebrovasc Dis 23: 136-139.

11. Kobayashi A, Iguchi M, Shimizu S, Uchiyama S (2012) Silent cerebral infarcts and cerebral white matter lesions in patients with nonvalvular atrial fibrillation. J Stroke Cerebrovasc Dis 21: 310-317.

12. Chou PS, Chen CH, Wu MN, Lin YH, Lai CL, et al. (2015) Determinants of cerebral white matter changes in patients with stroke. Intern Med J 45: 390-395.

13. Shrestha I, Takahashi T, Nomura E, Ohtsuki T, Ohshita T, et al. (2009) Association between central systolic blood pressure, white matter lesions in cerebral MRI and carotid atherosclerosis. Hypertens Res 32: 869-874.

14. Schmidt R, Fazekas F, Kleinert G, Offenbacher H, Gindl K, et al. (1992) Magnetic resonance imaging signal hyperintensities in the deep and subcortical white matter. A comparative study between stroke patients and normal volunteers. Arch Neurol 49: 825-827.

15. Takahashi W, Tsukamoto Y, Takizawa S, Kawada S, Takagi S. (2012) Relationship between chronic kidney disease and white matter hyperintensities on magnetic resonance imaging. J Stroke Cerebrovasc Dis 21: 18-23.

16. Awad IA, Johnson PC, Spetzler RF, Hodak JA (1986) Incidental subcortical lesions identified on magnetic resonance imaging in the elderly. II. Postmortem pathological correlations. Stroke 17: 1090-1097.

17. van Swieten JC, van den Hout JH, van Ketel BA, Hijdra A, Wokke JH, et al. (1991) Periventricular lesions in the white matter on magnetic resonance imaging in the elderly: A morphometric correlation with arteriolosclerosis and dilated perivascular spaces. Brain 114: 761-774.

18. Fazekas F, Kleinert R, Offenbacher H, Schmidt R, Kleinert G, et al. (1993) Pathologic correlates of incidental MRI white matter signal hyperintensities. Neurology 43: 1683-1689.

19. Fazekas F, Schmidt R, Scheltens P (1998) Pathophysiologic mechanisms in the development of age-related white matter changes of the brain. Dement Geriatr Cogn Disord 9 Suppl 1: 2-5.

20. Brown WR, Thore CR (2011) Review: Cerebral microvascular pathology in ageing and neurodegeneration. Neuropathol Appl Neurobiol 37: 56-74.

21. Schmidt R, Schmidt H, Haybaeck J, Loitfelder M, Weis S, et al. (2011) Heterogeneity in age-related white matter changes. Acta Neuropathol 122: 171-185.

22. van Dijk EJ, Breteler MM, Schmidt R, Berger K, Nilsson LG, et al. (2004) The association between blood pressure, hypertension, and cerebral white matter lesions: Cardiovascular determinants of dementia study. Hypertension 44: 625-630. 